OnLine Journal of Biological Sciences 7 (1): 21-29, 2007

ISSN 1608-4217

(C) 2007 Science Publications

\title{
Assessment of The Biological Integrity of The Native Vegetative Community In A Surface Flow Constructed Wetland Treating Industrial Park Contaminants
}

\author{
${ }^{1}$ C. C. Galbrand, ${ }^{2}$ A. M. Snow, ${ }^{2}$ A. E. Ghaly and ${ }^{1}$ R. Côté \\ ${ }^{1}$ School of Resources and Environmental Studies \\ ${ }^{2}$ Department of Process Engineering and Applied Sciences \\ Dalhousie University, Halifax, Nova Scotia, Canada, B3J 2X4
}

\begin{abstract}
A study was conducted to evaluate the biological integrity of a constructed wetland receiving landfill leachate and stormwater runoff from the Burnside Industrial Park, Dartmouth, Nova Scotia. The biological integrity of the constructed wetland was tested in the second growing season using vegetative community monitoring. The metrics analyzed were species diversity, species heterogeneity (dominance) and exotic/invasive species abundance. There was no significant difference in the plant species diversity between the constructed wetland and the reference site. However, the constructed wetland supported a higher plant species richness than the reference site. The top three species in the constructed wetland were tweedy's rush (Juncus brevicaudatus), soft rush (Juncus effusus) and fowl mannagrass (Glyceria striata). In total, these three species occupied $46.4 \%$ of the sampled population. The top three species in the reference site were soft rush (Juncus effusus), sweetgale (Myrica gale) and woolgrass (Scirpus cyperinus). In total, these three species occupied a more reasonable $32.6 \%$ of the sampled population. The reference site supported greater biological integrity as it had greater heterogeneity and a smaller abundance of exotic and invasive species compared to the constructed wetland (3.8\% versus $10.7 \%)$. Although poor heterogeneity and the presence of weedy, exotic species can be a sign of degraded biological health and future problems, these are also common indicators of a system simply undergoing early succession. As the constructed wetland matures, its plant biodiversity may actually decrease, but its integrity, as measured by exotic and invasive species abundance as well as heterogeneity, is expected to increase, so long as invasive species present in the constructed wetland remain controlled through weeding during the first few growing seasons.
\end{abstract}

Keywords constructed wetland, biological integrity, industrial park, landfill leachate

\section{INTRODUCTION}

Natural wetlands are ecosystems that are transitional between terrestrial and aquatic environments. They contain hydric soils, which are saturated with surface or groundwater for most of the year and support a wide variety of microorganisms, aquatic invertebrates and water tolerant plant species ${ }^{[1,}$ ${ }^{21}$. Nutrient cycling, retention of particulates, removal of elements and compounds, and the import and export of organic carbon are all biogeochemical functions of natural wetlands. On the other hand, constructed wetlands are engineered ecosystems composed of shallow bodies of slowly moving water, saturated substrates, emergent and submergent, water tolerant vegetation and animal life. They are designed to mimic natural wetlands and are established for a variety of purposes including wastewater treatment and habitat restoration $^{[3]}$. When designed properly, constructed wetlands are capable of effectively purifying wastewater using the same water quality amelioration functions carried out in natural wetland habitats ${ }^{[4,5]}$.

Biological integrity is defined as the ability of an ecosystem to support and maintain a balanced, integrated, and adaptive community of organisms having a species composition, diversity, and functional

Corresponding author: Professor A. E. Ghaly, Process Engineering and Applied Science Department, Dalhousie University, Halifax, Nova Scotia, Canada; Tel: (902) 494-6014; Fax: (902) 420-7639 
organization comparable to that of the natural habitat of the region ${ }^{[6,7]}$. It assumes that a decline in the values of an ecosystem's functions are primarily caused by human activity. The more an environment and it's original processes are altered, the less biological integrity it holds for the community as a whole. The biological integrity of an ecosystem is evaluated by comparing the condition of one or more of its taxonomic assemblages to that of a local, natural site. The major premise is that the community of plants and animals will reflect the underlying health of the ecosystem in which they live. Several different biological assemblages can be used to gauge the biological integrity in fresh water systems including: birds, fish, algae, amphibians, aquatic macroinvertebrates and plants. Of all these, the latter two are the most commonly used in wetland bioassessment $^{[8,9]}$.

The aim of this study was to evaluate the biological integrity of the native vegetative community in a constructed wetland receiving landfill leachate and stormwater runoff from the Burnside Industrial Park.

\section{MATERIALS AND METHODS}

Burnside Industrial Park: The Burnside Industrial Park located in Dartmouth, Nova Scotia is the largest industrial park in Atlantic Canada with over 1500 businesses supporting more than 25,000 employees. These businesses are a significant generator of solid waste, wastewater discharges and air pollution in the region $^{[10,}{ }^{11]}$. The Burnside Industrial Park was established in 1976 with no ecological health in mind, and had limited regard for the natural landscape of the area. As a result, many forested and wetland areas were cleared to make way for its development ${ }^{[12]}$. Several landfills (including the Burnside Drive landfill) were hastily implemented to accommodate increasing waste loads, and operated and decommissioned with little consideration for the environment ${ }^{[13]}$.

Burnside Landfill: The Burnside Drive landfill (now decommissioned and currently known as the Don Bayer Sports Field) is located near the northern boundary of the Burnside Industrial Park, at the corner of Akerley Boulevard and Burnside Drive (Fig. 1). This 5.4 ha open waste disposal site had accepted municipal, agricultural and industrial wastes (all of which were reportedly burned to reduce volume) from the Dartmouth Municipality. The dumpsite was graded, compacted and covered with two feet of soil upon closure, as was common in the day, with no regard for pollution control or aesthetics ${ }^{[14]}$. Since its closure in the 1970's, leachate from the decomposing waste beneath the sports field, as well as stormwater draining from a 55.1 hectare watershed surrounding the landfill ultimately discharge into Wright's Brook through stormwater ditches located on the western, northern and eastern borders of the sports field. Wright's Brook traverses $4.6 \mathrm{~km}$, passing through Enchanted and Flat lakes before discharging into the Bedford Basin of the Halifax Harbour. Water quality analyses of the stormwater ditches (Table 1) indicated that the wastewater contained elevated levels of iron, manganese, ammonia, and suspended solids ${ }^{[14]}$. This wastewater discharge has had visible adverse effects on Wright's Brook and the associated ecosystems.

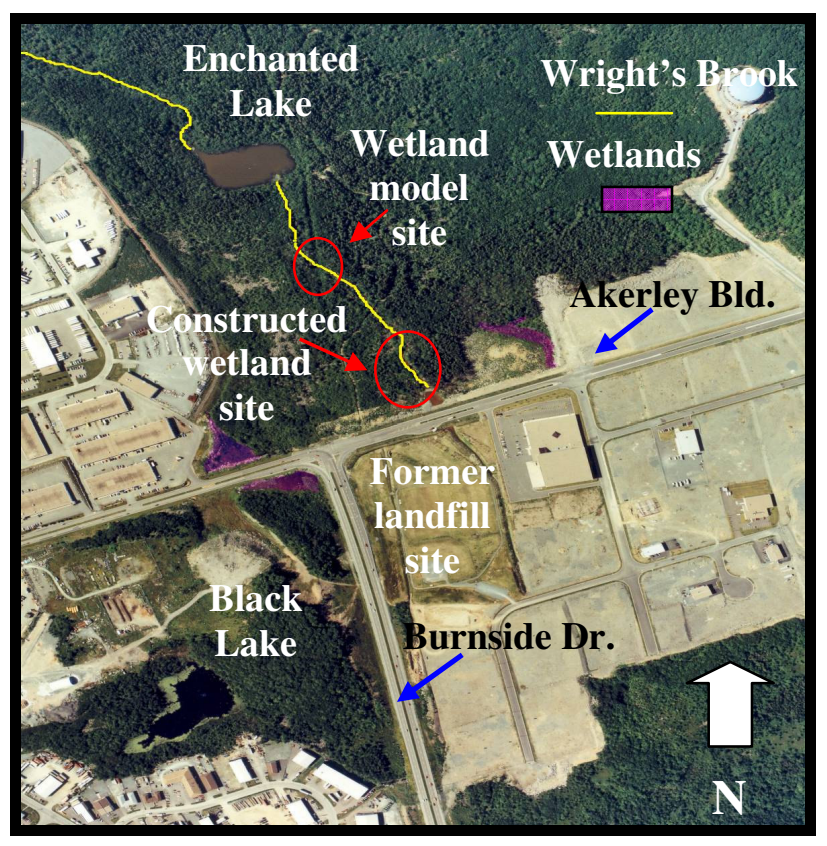

Fig. 1: Aerial photograph of the northern boundary of the Burnside Industrial Park (scale 1:10000) ${ }^{[15]}$

Constructed Wetland: To address the problem, a seven celled surface flow constructed wetland (approximately $5000 \mathrm{~m}^{2}$ in area) was constructed in the late fall of 2001 and spring of 2002 (Fig. 2). The wetland consists of a deep-water (greater than $1 \mathrm{~m}$ ) system separated by shallow interior earth berms of $2 \mathrm{~m}$ width, which were constructed in the marshy area receiving the wastewater. The wetland was designed to curve in a kidney shape in order to increase the length to width ratio to about 5 to 1 . The first cell was deeper than the others (approximately $1.5 \mathrm{~m}$ ) in order to facilitate the settling and accumulation of suspended 
solids. The till of the area was found to support 15 $25 \%$ silt/clay with dense to very dense consistency and a permeability of $10^{-4}$ to $10^{-6} \mathrm{~cm} / \mathrm{sec}^{[16]}$. It was, therefore, concluded that compaction of the soil would provide adequate lining for the site. The natural gravitational flow facilitated by the site topography negated the need for any mechanical infrastructure such as pumps. The biological integrity of the constructed wetland was tested in the second growing season of the site (spring of 2003) using vegetative community monitoring.

Table 1: Water quality results for samples taken from the Don Bayer sports field stormwater ditches in October $2000^{[14]}$

\begin{tabular}{lcc}
\hline Elements & Concentration* $(\mu \mathrm{g} / \mathrm{L})$ & Guidelines $^{[14]}$ \\
\hline Aluminum & 10.00 & $5-100$ \\
Boron & 57.33 & 200 \\
Calcium & 43300.00 & NGA \\
Chloride & 75370.00 & NGA \\
Chromium & 0.67 & $1-8.9$ \\
Cobalt & 2.00 & NGA \\
Iron & 6166.67 & 300 \\
Magnesium & 4000.00 & NGA \\
Manganese & 1800.00 & $1000-2000$ \\
Potassium & 2100.00 & NGA \\
Sodium & 41200.00 & NGA \\
Strontium & 190.00 & NGA \\
Zinc & 6.67 & 30 \\
\hline
\end{tabular}

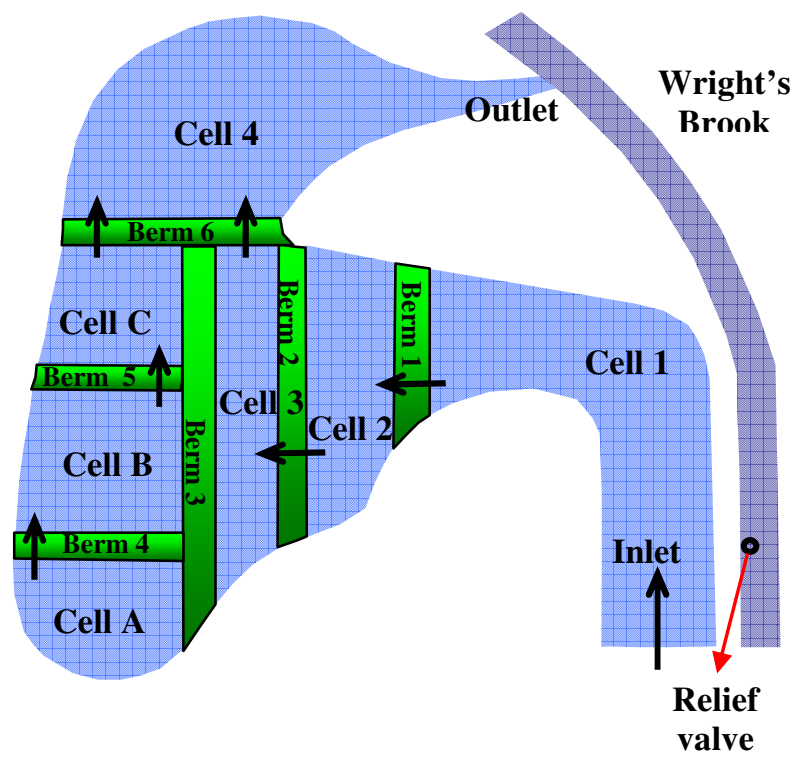

Fig. 2: Burnside wetland diagram.

Reference Wetland: To be effectively assessed, the data obtained from the constructed wetland must be compared to the data collected from a healthy, local reference site. The reference site was selected by examining the wetland inventories conducted by the Nova Scotia Wetland Mapping Protection Program (1988). Classifications were based on factors such as dominant vegetation, the presence depth and permanence of surface water, wetland size, topographic and hydrologic location, surrounding habitat, proportions and interspersion of cover, water and vegetation, and water chemistry. Based on these and other criteria, freshwater systems have been scored values between 36 to 108, with values greater than 60 perceived as having high biodiversity, high habitat value and overall ecological health ${ }^{[17]}$. As a result of its fitting classification and close location (approximately $25 \mathrm{~km}$ from the constructed wetland), marsh A-8 (in the Waverly Game Sanctuary) was selected as the reference site for the biological integrity assessment. Water samples from the site were submitted for fingerprint analysis to establish that the site would be an effective control, as disturbance is not always discernible to the eye.

Vegetation Sampling: The materials used for the vegetation sampling were: four $1 \mathrm{~m}$ long pieces of string, a $1 \mathrm{~m}$ long piece of string attached to a pencil, a $1 \mathrm{~m}^{2}$ squared quadrat, a $50 \mathrm{~m}$ measuring tape, a clipboard, datasheets, generated random number tables and plastic baggies. The plant identification guides used were Roland's Flora of Nova Scotia, Vol. I and II ${ }^{[18]}$, Aquatic and Wetland Plants of Northeastern North America, Vol. I and II ${ }^{[19]}$, and Newcomb's Wildflower Guide $^{[20]}$. Vegetation sampling of the constructed wetland and the reference site was conducted in July, 2003. The sampling regime used for the vegetation sampling was a stratified random sample. A stratified sample allows for a target area to be assessed while still remaining statistically viable by sampling at random ${ }^{[21]}$. The vegetated berms of the constructed wetland were the focus of the vegetation assessment.

A starting point was arbitrarily chosen and a reference line transect along the northern edge of the target communities was designated. Using excel, a random numbers table was generated. The first 3 random numbers (eliminating any repeated numbers or numbers that did not lead to the target areas) were used to locate the 3 line transects in the target areas set perpendicular to the reference line transect. Along each line transect, 10 randomly chosen quadrats, based on the same series of random numbers were sampled, eliminating any repeated numbers or numbers that exceeded the transect range. The quadrat was a $1 \mathrm{~m}^{2}$ metal frame, divided into 9 equal sections with $1 \mathrm{~m}$ 
long sections of string. Within each quadrat, the string with the pencil attached was dropped $1 \mathrm{~m}$ above the quadrat, sampling each of the 9 sectors. The plant located at the tip of the pencil was identified and recorded as described by Murphy ${ }^{[22]}$ and Underwood ${ }^{[21]}$. Those plants not identifiable in the field were labeled and bagged for later identification. In total, 270 sectors were sampled for each site.

Metrics of Biological Integrity: The biological integrity of the constructed wetland was assessed by examining and comparing the vegetation populations of the constructed wetland and those of the reference wetland via three metrics commonly used in biological integrity assessments. The metrics analyzed were species diversity, species heterogeneity (dominance) and exotic invasive species abundance ${ }^{[8]}$.

Species Diversity: The data collected was assessed for plant species diversity ( $\alpha$-diversity) using the following Shannon-Weiner index ${ }^{[22,23]}$ :

$$
H^{\prime}=-\Sigma\left[p_{i}\left(\ln p_{i}\right)\right]
$$

Where:

$\mathrm{H}^{\prime}$ = Shannon-Weiner diversity index

$\mathrm{p}_{\mathrm{i}}=$ proportional abundance of a given species (i)

The proportional abundance (pi) was calculated as follows:

$$
\mathrm{p}_{\mathrm{i}}=\mathrm{n}_{\mathrm{i}} / \mathrm{N}
$$

Where:

$\mathrm{n}_{\mathrm{i}}=$ the number of individuals of a given species (i)

$\mathrm{N}=$ the total number of individuals of all species

The Shannon-Weiner index is a measure of the proportional abundance of each species. It assumes that: (a) all individuals are sampled at random, (b) all individuals are sampled from infinitely large populations and (c) all species present will be sampled. For a large number of samples, the values will have a log-normal distribution, which is convenient as parametric statistics only work if the data has a lognormal distribution ${ }^{[22,23]}$. The higher the ShannonWeiner index, the more diverse the system is implied to be in terms of number of species. In order to accurately measure the difference in diversity between the two communities, the variance in diversity was calculated for both sites using the following formula ${ }^{[22]}$ :

$$
\mathrm{H}^{\prime}{ }_{\text {var }}=\mathrm{N}^{-1}\left\{\Sigma \mathrm{p}_{\mathrm{i}}\left(\ln \mathrm{p}_{\mathrm{i}}\right)^{2}-\left[\Sigma \mathrm{p}_{\mathrm{i}}\left(\ln \mathrm{p}_{\mathrm{i}}\right)\right]^{2}\right\}-\left\{\left(2 \mathrm{~N}^{2}\right)^{-1}\{\mathrm{~S}-1]\right\}
$$

Where:

$\mathrm{H}^{\prime}{ }_{\text {var }}=$ variance in diversity

$\mathrm{N}=$ the total number of individuals of all species

$\mathrm{p}_{\mathrm{i}}=$ proportional abundance of a given species (i)

$\mathrm{S} \quad=$ species richness

Once the variances were calculated, the diversity of the two sites was statistically compared using parametric t-test statistics. The t-test determines whether the means of the two samples are significantly different from one another by comparing the distribution of values derived from the samples to a statistical distribution (the t-distribution). In the case of the Shannon-Weiner comparison, the formula used for calculating the t-statistic was as follows ${ }^{[22]}$.

$$
\mathrm{t}=\frac{\left[\mathrm{H}_{\text {ref site }}^{\prime}-\mathrm{H}_{\text {constructed wetland }}^{\prime}\right]}{\left[\mathrm{H}_{\text {var }}^{\prime}(\text { ref site })+\mathrm{H}_{\text {var }}^{\prime}(\text { constructed wetland })\right]^{0.5}}
$$

Where:

$\underline{\mathrm{t}}=\underline{\mathrm{t}}$-statistic

$\mathrm{H}^{\prime}=$ Shannon-Weiner diversity index

The degrees of freedom which exist for the test were then calculated in order to gauge the accuracy of the test. The greater the degrees of freedom, the more accurate the test $^{[22]}$.

$$
\mathrm{df}=\frac{\left[\mathrm{H}_{\mathrm{var}}^{\prime}(\text { ref site })+\mathrm{H}_{\mathrm{var}}^{\prime}(\text { constructed wetland })\right]}{\frac{\left[\mathrm{H}_{\mathrm{var}}^{\prime}(\text { ref site })\right]^{2}}{\mathrm{~N}_{\text {ref site }}}+\frac{\left[\mathrm{H}_{\mathrm{var}}^{\prime}(\text { constructed wetland })\right]^{2}}{\mathrm{~N}_{\text {constructed wetland }}}}
$$

Where:

Df $=$ degrees of freedom

$\mathrm{H}^{\prime}$ var $=$ variance in diversity

$\mathrm{N} \quad=$ the total number of individuals of all species

The values were then compared to a table of critical values of the t-distribution ( $95 \%$ confidence interval). If the values were greater than the relative values in the table, it could be implied that the observed $\mathrm{t}$-value was greater than the expected (random) t-values, and the two sites compared were significantly different in terms of their species diversity, with the site supporting the higher value of H' supporting the greater species diversity. Likewise, if the values were close to 
the values in the table of critical values, then the sites could be deemed statistically similar ${ }^{[22]}$. This latter result was highly desirable as it was the aim of this study to produce a site with biological integrity (gauged in this case through biodiversity) similar to that of a natural wetland site.

Heterogeneity (Dominance): The heterogeneity of the constructed wetland site and the reference site was assessed using the following equation ${ }^{[22]}$ :

$$
\text { Heterogenity }=\frac{\text { abundance of the top } 3 \text { species }}{\text { total number of species }} \times 100
$$

Exotic Species Abundance: The data collected during the vegetation sampling was also assessed for total proportional abundances of invasive and exotic species. This was assessed using the following equation ${ }^{[22]}$ :

Proportional abundance $=\frac{\text { total number of exotic species }}{\text { total number of species }} \times 100$

\section{RESULTS AND DISCUSSION}

The results of the biological integrity assessment of the vegetation populations are presented in Table 2. The species abundance and richness are illustrated in Fig. 3. The population heterogeneity and exotic species abundance are illustrated in Figs. 4 and 5.

Species Diversity: Biodiversity is often sited as the preeminent gauge of biological integrity. All biological integrity assessments tend to integrate some gauge of biodiversity as part of their study ${ }^{[8,22,24-26]}$. The H' values for the constructed wetland and reference wetland were perceptibly close (2.069 and 2.053). With little scrutiny, one could easily deduce that in terms of species diversity, the sites were very similar. This was confirmed statistically through the use of t-tests (Table 2). The derived hypotheses were:

$\mathrm{H}_{0}$ : $\quad$ Significant differences exist between the plant species diversities of the sites

$\mathrm{H}_{1}$ : No significant difference between the plant species diversity of the sites

The calculated test statistic must be higher than the critical $\underline{\mathrm{t}}-$-value $(\mathrm{p}$ value $=0.05$ ) in order for the null hypothesis to be rejected ${ }^{[22]}$. The t-statistic value of 0.071 which was significantly less than the critical tvalues of 1.960 and 1.980 ( $\mathrm{p}$ value $=0.05$ ), indicated that there was no significant difference between the plant species diversities in the two wetland sites.

Table 2: The results of the biological integrity assessment of the wetland plants

\begin{tabular}{lcc}
\hline Metric & $\begin{array}{c}\text { Constructed } \\
\text { wetland }\end{array}$ & $\begin{array}{c}\text { Reference } \\
\text { site }\end{array}$ \\
\hline Total density (N) & 261 & 267 \\
Species richness & 46 & 41 \\
Species diversity (H') & 2.069 & 2.053 \\
Variance (H' ${ }_{\text {var }}$ & 0.025 & 0.025 \\
Heterogeneity (Dominance) & $47 \%$ & $32 \%$ \\
Exotic species abundance & $10.7 \%$ & $3.8 \%$ \\
\hline
\end{tabular}

$\mathrm{t}$ statistic $(\mathrm{t})=0.071$

Degrees of Freedom $(\mathrm{df})=530$

Critical t values $(\alpha=0.05)=1.960$ and 1.980

Heterogeneity (Dominance): Natural, healthy wetlands not only support diverse populations of plants, but balanced proportions of species. Disturbed sites, especially those undergoing early succession such as the constructed wetland site, can often support high diversity, but in skewed proportions (e.g. domination of roadside ditches by duckweed or purple loosestrife). The domination of one or a few species can be early signs that vegetative populations are becoming outcompeted by invasive species. Sites that are more heterogeneous are more likely to maintain biodiversity by preventing competitive exclusion ${ }^{[27,28]}$. Hence, the proportional abundance and distribution of plant species can be an important indicator of system health ${ }^{[22,26,29]}$ and can lead to effective and informed management decisions concerning site maintenance.

The top three species in the constructed wetland were tweedy's rush (Juncus brevicaudatus) with 60 individuals sampled, soft rush (Juncus effusus) with 44 individuals sampled, and fowl mannagrass (Glyceria striata) with 17 individuals sampled. In total, these three species occupied $46.4 \%$ of the sampled population. The top three species in the reference site were soft rush (Juncus effusus) with 38 individuals sampled, sweetgale (Myrica gale) with 27 individuals sampled and woolgrass (Scirpus cyperinus) with 22 individuals sampled. In total, these three native species occupied a more reasonable $32.6 \%$ of the sampled population $^{[26]}$. Therefore, the reference wetland site supported higher heterogeneity than the constructed wetland site.

Although the two wetland sites appeared to be equally biodiverse and more species were found in the constructed wetland site overall, nearly $50 \%$ of the 
constructed wetland site is occupied by 3 species, which indicates that the site is not as healthy as indicated by the richness and diversity results. The results indicated that although currently diverse, the distribution of the species is skewed. This is often viewed as a sign that the biodiversity of a site is under threat as other species are being out-competed by aggressive stands ${ }^{[26,29,}{ }^{30]}$. The tweedy's rush in particular seems to have a ruling presence in the constructed wetland. However, the tweedy's rush, soft rush and mannagrass are all notably native plants which are not reported to exhibit invasive or aggressive characteristics $^{[18,31]}$. Had any of these species been exotic or known to exhibit invasive tendencies, there might have been cause for greater concern. Regardless, the heterogeneity of the constructed wetland is far from ideal. Perhaps as the site matures and the slower growing species become more established, the vegetative heterogeneity will improve ${ }^{[18,24,}{ }^{31]}$. However, if the tweedy's rush or any other species continues to show signs of increasing domination, control measures such as weeding may need to be implemented.

Exotic Species Abundance: Wetlands which support biological integrity support healthy assemblages of native plant life. Conversely, sites supporting abundant populations of exotic and invasive species are perceived as systems of poor health, suffering from what is termed "biological pollution". Abundant invasive and exotic species tend to out-compete native vegetation and destroy the natural diversity (and habitat) of the community $^{[24,31]}$.

The constructed wetland had a $10.73 \%$ abundance of exotic and invasive species while the reference site had only a $3.75 \%$ abundance of exotic and invasive species. Although a community ideally would support $100 \%$ native species, this is rarely seen even in the most pristine environments, as most exotic plant seeds have highly adapted transport mechanisms ${ }^{[24]}$. The sampling regime may have brought to light the potential problem of exotic, aggressive species out-competing native vegetation in the constructed wetland in the future.

The exotic and/or aggressive species sampled in the constructed wetland included reed canary grass (Phalaris arundinacea), oxeye daisy (Chrysanthemum leucanthemum), broad-leaved cattail (Typha latifolia), stinkweed (Thlaspi arvense), timothy hay (Phleum pratense), dame's rocket (Hesperis matronalis), Canada thistle (Cirsium arvense), coltsfoot (Tussilago farfara), horsetail (Equisetum arvense), field mustard (Brassica rapa) and yellow hawkweed (Hieracium florentinum). Of these, reed canary grass and broad-leaved cattail are possible invaders, especially in disturbed areas ${ }^{[31]}$. More aggressive control of these species may become necessary in the future in order to prevent them from overtaking the established native vegetation in the site. However, none of these species were present in high numbers, so it is just as likely that their presence is simply a symptom of early succession.

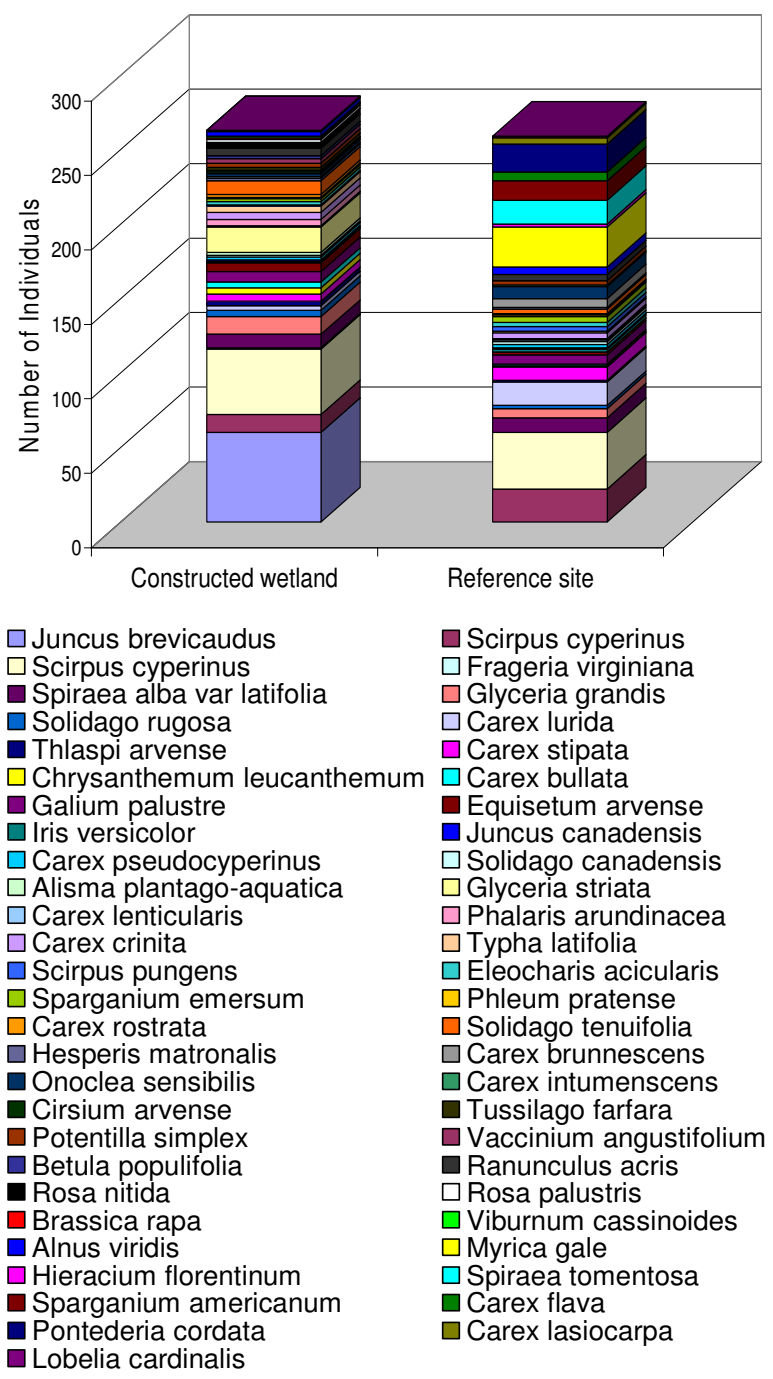

Fig. 3: Vegetation species richness in constructed wetland and reference site

Succession occurs when areas suffer a disturbance such as a fire or tornado (or in this case, excavation), which removes the existing vegetation. The first colonizers in areas are typically aggressive species 
which are adapted to take advantage of full sunlight exposure and inhabit bare areas quickly ${ }^{[28]}$.. However, as a disturbed site matures, and space and light availability become lessened, these colonizers often give way to more hardy, slow-spreading species which are better light competitors. Hence, as the constructed wetland matures, its plant biodiversity may actually decrease. However, its integrity, as measured by exotic and invasive species abundance as well as heterogeneity, may actually increase, so long as invasive species do not overwhelm the site ${ }^{[28]}$.

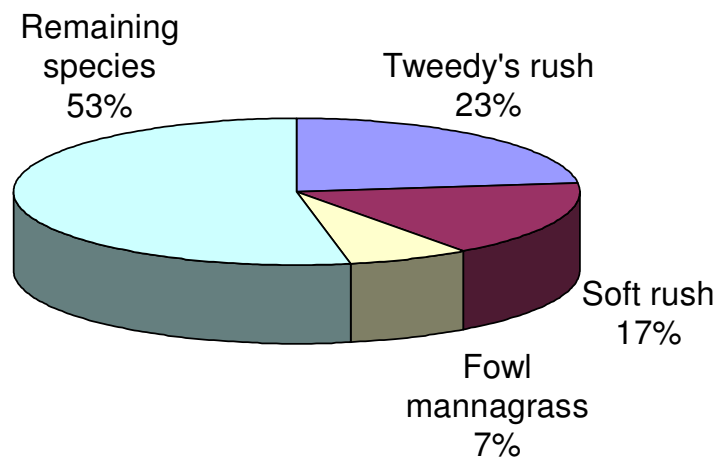

(a) Constructed wetland

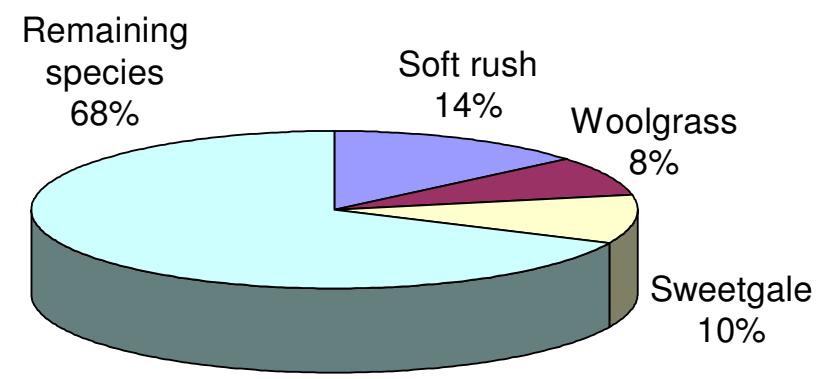

(b) Reference site

Fig. 4: Abundance of top three plant species in the constructed wetland and reference site

\section{CONCLUSIONS}

There was no significant difference in the plant species diversity between the constructed wetland and the reference site. However, the constructed wetland supported a higher plant species richness than the reference site. The top three species in the constructed wetland were tweedy's rush (Juncus brevicaudatus), soft rush (Juncus effusus) and fowl mannagrass (Glyceria striata). In total, these three species occupied
$46.4 \%$ of the sampled population. The top three species in the reference site were soft rush (Juncus effusus), sweetgale (Myrica gale) and woolgrass (Scirpus cyperinus). In total, these three species occupied a more reasonable $32.6 \%$ of the sampled population. The reference site supported greater biological integrity as it had greater heterogeneity and a smaller abundance of exotic and invasive species compared to the constructed wetland $(3.8 \%$ versus $10.7 \%)$. Although poor heterogeneity and the presence of weedy, exotic species can be a sign of degraded biological health and future problems, these are also common indicators of a system simply undergoing early succession. As the constructed treatment wetland matures, its plant biodiversity may actually decrease, but its integrity, as measured by exotic and invasive species abundance as well as heterogeneity, is expected to increase, so long as invasive species present in the constructed wetland site remain controlled through weeding during the first few growing seasons.

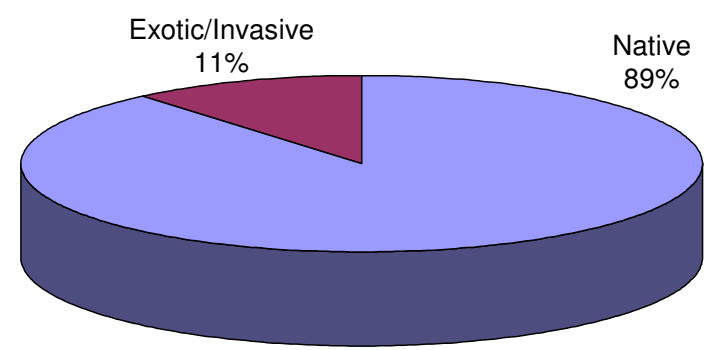

(a) Constructed wetland

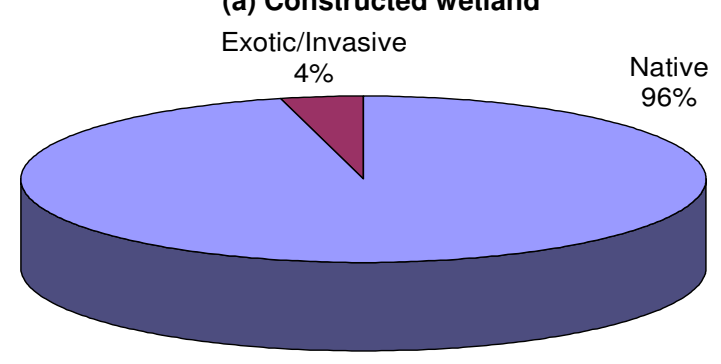

(b) Reference site

Fig. 5: Abundance of exotic/invasive plant species in the constructed wetland and reference site

\section{ACKNOWLEDGEMENTS}

This study was made possible through the financial support of the ELJB Foundation of Montréal and the TD Bank Friends of the Environment Foundation of Toronto. 


\section{REFERENCES}

1. EPA. 2000. Guiding Principles for Constructed Treatment Wetlands. [online] Available: http://www.epa.gov/owow/wetlands/constructed/gu ide.html [4 February 2004].

2. Cowardin L.M., V. Carter, F.C. Golet and E.T. LaRoe. 1979. Classification of Wetlands and Deepwater Habitats of the United States. U.S. Fish and Wildlife Service, Washington, DC.

3. Kadlec, R. H. and R. L. Knight. 1996. Treatment Wetlands. CRC Press LCC, Boca Raton, Florida

4. Osmond, D.L., D.E. Line, J.A. Gale, R.W. Gannon, C.B. Knott, K.A. Bartenhagen, M.H. Turner, S.W. Coffey, J. Spooner, J. Wells, J.C. Walker, L.L. Hargrove, M.A. Foster, P.D. Robillard and D.W. Lehning. 1995. Mining and Acid Mine Drainage: Watersheds: Water, Soil and Hydro-Environmental Decision Support System [online]. Available: http://h2osparc.wq.ncsu.edu/wetland/aqlife/mining. html\#amdm [2002, 2 February]

5. Hammer, D.A. 1992. Creating Freshwater Wetlands. Lewis Publishers, London, England.

6. Karr, J.R. and D.R. Dudley. 1981. Ecological perspectives on water quality goals. Environmental Management, 5: 55-68.

7. Frey, D. 1977. Biological integrity of water: a historical approach. In: R. K. Ballentine and L.J. Guarraia (editors). The Integrity of Water. Proceedings of a Symposium, March 10-12, 1975, U.S. Environmental Protection Agency, Washington, D.C. p. 127-140

8. USEPA. 2002. Methods for Evaluating Wetland Condition: Developing Metrics and Indexes of Biological Integrity. EPA-822-R-02-016 [online]. Available: http://www.epa.gov/waterscience/criteri a/wetlands/6Metrics.pdf [2003, 22 January].

9. USEPA. 2002. Methods for Evaluating Wetland Condition: Introduction to Wetland Biological Assessment.EPA-822-R-02-014 [online]. Available: http://www.epa.gov/waterscience/criteri a/wetlands/1Introduction.pdf [2003, 22 January].

10. Côté, R., T. Kelly, H. Reid and T. Smolenaars. 1996. The Industrial Park as an Ecosystem: Sectoral Case Studies. Dalhousie University, School for Resource and Environmental Studies, Halifax, Nova Scotia

11. Noronha, J. 1999. Scavengers and Decomposers in an Industrial Park System: A Case Study of Burnside Industrial Park. Dalhousie University, School for Resource and Environmental Studies, Halifax, Nova Scotia
12. Grant, J. 1996. Designing industrial parks for the future. Plan Canada, 36(3): 17-22.

13. Sibbald, J. 2003. Personal Communication. Pollution Prevention Coordinator, Environment and Right of Way Services, Public Works and Transportation, Halifax Regional Municipality.

14. Ghaly, A.E. and R. Côté. 2001. Engineered Wetland Technology for Treatment of Industrial Park Contaminants: A Progress Report. Dalhousie University, Halifax, Nova Scotia.

15. HLIS. 2003. Topographic Map, Dartmouth, Nova Scotia. Halifax Land Information Services, Government of Nova Scotia, Halifax, Nova Scotia.

16. Lewis, M.C.F., B.B. Taylor, R.R. Stea, G.G.J. Fader, R.J. Horme, S.G. MacNeil and J.G. Moore. 1998. Earth Science and Engineering: Urban Development in the Metropolitan Halifax Region. Minerals and Energy Branch, Nova Scotia Natural Resources, Halifax, Nova Scotia.

17. WMPP. 1988. Nova Scotia Wetlands Atlas. Wetlands Mapping Protection Program, Canadian Wildlife Service, Environment Canada, Sackville, Nova Scotia.

18. Zinck, M. 1998. Roland Flora of Nova Scotia, Vol. I and II. Nimbus Publishing and the Nova Scotia Museum, Halifax, Nova Scotia.

19. Crow, G.E. and C.B. Hellquist. 2000. Aquatic and Wetland Plants of Northeastern North America, Vol. I and II. The University of Wisconsin Press, Madison, Wisconsin.

20. Newcomb, L. 1977. Newcomb's Wildflower Guide. Little, Brown and Company Ltd., Toronto, Ontario.

21. Underwood, A.J. 1997. Experiments in Ecology: Their logical design and interpretation using analysis of variance. Cambridge University Press, New York, New York.

22. Murphy, S.D. 1999. ERS 380 Restoration Ecology Course Reader. University of Waterloo, Waterloo, Ontario.

23. Cousins, S.H. 1991. Species diversity measurement: Choosing the right index. Trends in Ecology and Evolution, 6: 190-192.

24. Daigle, J.M. and D. Havinga. 1996. Site Level Restoration Planning and Implementation. In: J.M. Daigle and D. Havinga (editors). Restoring Nature's Place: A Guide to Naturalizing Ontario's Parks and Greenspace. Ontario Parks Association, Toronto, Ontario. p. 61-92.

25. USEPA. 2002. Biological Assessment of Wetlands [online]. Available: http://www.epa.gov/owow.wet lands/bawwg/ [2003, 22 January]. 
26. USEPA. 2002. Methods for Evaluating Wetland Condition: Using Vegetation To Assess Environmental Conditions in Wetlands. EPA-822R-02-020 [online]. Available: http://www.epa. gov/waterscience/criteria/wetlands/10Vegetation.p df [2003, 22 January].

27. Stevens, M.H.H and W.P. Carson. 2002. Resource quantity, not resource heterogeneity, maintains plant diversity. Ecology Letters, 5: 420-426.

28. Crawley, M.J. 1997. Structure of plant communities. In: M. J. Crawley (editor). Plant Ecology. Blackwell Science, Oxford, England. p. 475-531.

29. Osmond, D.L., D.E. Line, J.A. Gale, R.W. Gannon, C.B. Knott, K.A. Bartenhagen, M.H. Turner, S.W. Coffey, J. Spooner, J. Wells, J. C., Walker, L. L. Hargrove, M.A. Foster, P.D. Robillard, and D.W. Lehning. 1995.Biomonitoring Watersheds: Water, Soil and Hydro-Environmental Decision Support System [online]. Available: http://h2osparc.wq.ncs u.edu/info/biomon.html [2002, 2 February].
30. Carlisle, B.K. 1998. Wetland Ecological Integrity: An Assessment Approach. The Coastal Wetlands Ecosystem Protection Project [online]. Available: http://www.state.ma.us/czm/wetlandecologicalinte grity.pdf [2003, 11 March]

31. Hunhorst, G. 1993. Wetland Planting Guide for the Northeastern United States: Plants for Wetland Creation, Restoration and Enhancement. Environmental Concern Inc., Maryland. 